\title{
Prevalence of PTSD Among Adolescent Boys in Selected Secondary Schools in Machakos County, Kenya
}

\author{
Assumptor Mukangi ${ }^{1,}$,, Stella Nyagwencha ${ }^{2}$, Mary Mogute ${ }^{1}$ \\ ${ }^{1}$ School of Humanities and Social Sciences, Daystar University, Nairobi, Kenya \\ ${ }^{2}$ School of Humanities and Social Sciences, United States International University-Africa, Nairobi, Kenya
}

Email address:

assumptorconsolata@yahoo.co.uk (A. Mukangi)

${ }^{*}$ Corresponding author

\section{To cite this article:}

Assumptor Mukangi, Stella Nyagwencha, Mary Mogute. Prevalence of PTSD Among Adolescent Boys in Selected Secondary Schools in Machakos County, Kenya. American Journal of Applied Psychology. Vol. 9, No. 5, 2020, pp. 140-144. doi: 10.11648/j.ajap.20200905.12

Received: September 15, 2020; Accepted: September 25, 2020; Published: October 12, 2020

\begin{abstract}
Background: Adolescents throughout the world are at risk of developing PTSD. PTSD has detrimental long term effects on every facet of life and has been shown to negatively impact the various areas of life. These areas often include: academic performance, cognitive abilities, emotion regulation and behavioural regulation. In adolescents, PTSD has particularly been implicated in high dropout rates which subsequently leads to poverty, fewer opportunities and a decreased lifespan. Objective: The purpose of this study was to establish the prevalence of PTSD among adolescent boys in selected secondary schools in Machakos County, Kenya. Methods: Two secondary schools were conveniently sampled with a total of 976. The adolescent boys were aged 14-17-years. The respondents filled a Socio-Demographic Questionnaire (SDQ) and the Child PTSD Symptom Scale-V-Self Report (CPSS-V-SR) which screened for PTSD symptoms. Results: The findings showed that the prevalence of PTSD was at 27.6\%. The findings also showed that respondents who lived in other counties (exclusive of Nairobi County and Machakos County) had the least frequency of 42 (15.6\%) but reported the highest mean PTSD symptoms at $24.5( \pm 24.5)$ and a statistically significant mean difference established in the counties $p<0.006$. Conclusion: The need for psychotherapy in secondary schools is therefore essential in order to alleviate PTSD prevalence. This is also crucial in order to buffer adolescents from comorbid diseases and psychological disorders.
\end{abstract}

Keywords: PTSD, Prevalence, Adolescents, Boys, Secondary Schools, Kenya

\section{Introduction}

Exposure to Potentially Traumatic Events (PTEs) inevitably leads to Post-Traumatic Stress Disorder (PTSD) [1]. PTSD has been linked to poor cognitive development, deterioration of cognitive abilities and the inability to regulate emotions and behaviour [2]. PTSD has also been implicated in the neurobiology dysregulation and has been linked to physical comorbidities with diseases such as obesity, cardiovascular disease, hypertension, chronic musculoskeletal pain, attachment, relationship quality and, a reduced lifespan [3]. Furthermore, PTSD has been implicated in the development of other mental disorders such as depression, substance abuse, anxiety, somatization and psychosis [4, 5]. These comorbid diseases and disorders further suppress the health and wellbeing of the victim(s) and debilitate every area of the individual's life [4].

Research on the prevalence of PTSD among adolescents has often varied. The global outlook shows that PTSD is on the rise. Studies, reviews and meta-analysis have set to investigate the prevalence of PTSD. In one such metaanalysis of 72 peer-reviewed studies with 3,563 participants. The prevalence was documented at $15.9 \%$ [6]. Great variation emerged between trauma type and gender. The study also found that boys who encountered noninterpersonal Potentially Traumatic Events (PTE) were at lower risk of presenting with PTSD symptoms at $8.4 \%$ whilst girls exposed to interpersonal trauma had the highest risk of presenting with PTSD symptoms at the prevalence rate of $32.9 \%$. Overall, those at a higher risk were girls and those exposed to interpersonal traumatic events. This finding was consistent with other studies in the area [7]. The metaanalysis also showed that girls were twice as likely to present 
with PTSD symptoms. Girls were also four times more likely to experience high impact traumatic events (sexual trauma) as compared to their male counterparts.

Consistent with the meta-analysis, a global outlook on PTSD indicated that both the prevalence of PTSD and the lifetime exposure to interpersonal violence were on the rise [8]. In this national sample of adolescents aged 13-17 in the United States, 6,483 adolescent-parent pairs were recruited onto the study. The findings indicated that traumatic events had been experienced by $61.8 \%$. The findings were consistent with the meta-analysis, and showed that PTSD was more prevalent among females than in males at $7.3 \%$ vs $2.2 \%$. PTSD was also common amongst adolescents who had encountered interpersonal violence.

In 2014, it was documented that adolescents in Africa had a PTSD prevalence of $20.1 \%$ falling second place after Canada [9]. In a cross-sectional survey that assessed risk factors and PTSD prevalence in Kenyan households, the prevalence among youth was documented at 10.6\% [10]. These findings indicate the need to treat PTSD with immediate effect using interventions that are brief and easily administered. By treating PTSD in its early stages, the debilitating effects can be reduced with comorbid diseases and disorders prevented and reduced. For these reasons, the purpose of this study was to establish the prevalence of PTSD among adolescent boys in selected secondary schools in Machakos County, Kenya.

\section{Procedure and Methods}

The procedures and methods used for the study are outlined below.

\subsection{Sample}

The respondents' were recruited from two secondary schools in Machakos County. The schools were selected because they had many students enrolled. Both schools were also similar in characteristics: they were both located in Machakos County and were both district boys' schools. A total of 976 students were screened. Those who met the inclusion criteria with an age range of 14-17-years were 269. The study approvals were obtained from Daystar University Ethics board, NACOSTI, the Ministry of Education and the respective schools. The respondents' provided assent to participate whilst the school administration provided consent on behalf of the students. The respondents' had a mean age of 15.84 years $(\mathrm{SD}=1.01)$. The school Principals announced to the students that research would be conducted. The researcher and assistants were given access. The researcher and assistants explained the goal of the study. Students who were interested in participating were issued with assent forms which they signed before they proceeded to fill the screening tools.

\subsection{Procedure and Methods}

The researcher and assistants moved from class to class. They explained to the students the requirements of the study and screened students who were interested in participating. The researcher and assistants readout the statements and allowed time for the students to respond. This was done to ensure that the respondents understood the questions.

\subsection{Tools/Instruments}

The instruments selected for the study are hereby outlined. This included the Socio-demographic Questionnaire (SDQ) developed by the researcher and the Child PTSD Symptom Scale-V-Self Report (CPSS-V-SR).

\subsubsection{Socio-demographic Questionnaire (SDQ)}

Respondents were asked to provide information on socio-demographic characteristics. The SDQ used was developed by the researcher and included information relating to age, religion/denomination, class, caregiver, the number of siblings the respondents' had and county of residence.

\subsubsection{Child PTSD Symptom Scale-V-Self Report (CPSS-V-SR)}

To assess for PTSD symptoms, respondents were administered the Child PTSD Symptom Scale-V-Self Report (CPSS-V-SR) [11]. The instrument has two sections: a trauma screen and PTSD symptoms screen. The instrument should be rated with reference to the index traumatic event that affected the respondent the most. The 20 items are related to the DSM-V symptom criteria for PTSD namely: hyperarousal, re-experiencing, avoidance and changes in cognition and mood. These symptoms are rated on a 4-point Likert scale that ranged from 0-4. A score of 0 means (not at all) whilst a score of 4 implies (6 times a week or almost always). The CPSS-V-SR has been shown to have good internal consistency of $(\alpha=0.92)$; with a test-retest reliability of $(\mathrm{r}=0.80)$ [11].

Scoring of the CPSS-V-SR is as follows: minimum symptoms are scored $0-10$, mild PTSD symptoms are rated 11-20; moderate PTSD symptoms fall under a score of 21 40; severe PTSD symptoms are categorized as 41-60 whilst very severe PTSD symptoms are scored 61-80. To get the PTSD symptom category for the respondents, the 20 -items are summed up. The instrument has a minimum of 0 score and a maximum of 80 denoting the severity of the symptoms.

\subsubsection{Data Analysis}

To find out the age distribution of the respondents, a frequency distribution illustrating their age was presented. The frequencies relating to the respondents' PTSD symptoms was illustrated. Descriptive statistics were used to analyze the respondents' socio-demographic characteristics by using SPSS version 21 .

\section{Results}

The study sought to establish the socio-demographic characteristics of the respondents in comparison to their PTSD scores (See Table 1). 
Table 1. Socio-Demographic Characteristics of the Respondents.

\begin{tabular}{|c|c|c|c|c|c|c|c|}
\hline \multirow{2}{*}{ Socio-demographic Variables } & \multicolumn{4}{|c|}{ Total } & \multicolumn{3}{|c|}{ Anova results } \\
\hline & $\mathbf{N}$ & $\%$ & Mean & SD & Statistic & DF & $\mathbf{P}$ \\
\hline \multicolumn{8}{|l|}{ Age } \\
\hline 14 years & 24 & 8.9 & 20.8 & 12.1 & 0.644 & 3,265 & 0.587 \\
\hline 15 years & 70 & 26.0 & 20.7 & 13.5 & & & \\
\hline 16 years & 90 & 33.5 & 20.5 & 13.8 & & & \\
\hline 17 years & 85 & 31.6 & 23.0 & 11.5 & & & \\
\hline \multicolumn{8}{|l|}{ Religion/Denomination } \\
\hline Catholic & 35 & 13.0 & 24.2 & 8.6 & 1.072 & 2,266 & 0.344 \\
\hline Muslim & 12 & 4.5 & 19.3 & 11.7 & & & \\
\hline Protestant & 222 & 82.5 & 21.0 & 13.5 & & & \\
\hline \multicolumn{8}{|l|}{ Caregiver } \\
\hline Father & 5 & 1.9 & 23 & 7.7 & 1.154 & 3,265 & 0.328 \\
\hline Guardian/Relative & 11 & 4.1 & 25.4 & 20.3 & & & \\
\hline Mother & 32 & 11.9 & 24.3 & 12.2 & & & \\
\hline Parents & 221 & 82.2 & 20.7 & 13.9 & & & \\
\hline \multicolumn{8}{|l|}{ Siblings } \\
\hline None or one & 73 & 27.1 & 22.1 & 14.5 & 0.35 & 2,266 & 0.705 \\
\hline Two to three & 146 & 54.3 & 20.8 & 12.5 & & & \\
\hline Four or more & 50 & 18.6 & 22.0 & 10.9 & & & \\
\hline \multicolumn{8}{|l|}{ Form } \\
\hline Form 1 & 98 & 36.4 & 22.0 & 14.5 & 0.358 & 2,266 & 0.699 \\
\hline Form 2 & 98 & 36.4 & 21.4 & 12.5 & & & \\
\hline Form 3 & 73 & 27.1 & 20.4 & 10.9 & & & \\
\hline \multicolumn{8}{|l|}{ Months at school } \\
\hline $\begin{array}{l}<=12 \\
13 \text { to } 24\end{array}$ & $\begin{array}{l}97 \\
102\end{array}$ & 36.1 & 22.3 & $\begin{array}{l}14.5 \\
116\end{array}$ & 0.383 & 2,266 & 0.682 \\
\hline $24+$ & 70 & 26.0 & 20.8 & 12.4 & & & \\
\hline \multicolumn{8}{|l|}{ County } \\
\hline Machakos & 93 & 34.6 & 18.0 & 11.9 & 5.223 & 2,266 & $0.006 *$ \\
\hline Nairobi & 134 & 49.8 & 22.7 & 12.7 & & & \\
\hline Other Counties & 42 & 15.6 & 24.5 & $14.2 \mathrm{~h}$ & & & \\
\hline
\end{tabular}

* Statistically significant at $\mathrm{p}<0.05$

The table shows the distribution of PTSD scores. An Anova test established a significant mean difference between the respondents' county of residence at $p=0.006$. There were no significant mean differences established between the respondents' age, religion/ denomination, caregiver, siblings, class and the duration they had been at the schools.

The study also sought to establish the prevalence of PTSD (See Table 2).

Table 2. Prevalence of PTSD Symptoms among Adolescents.

\begin{tabular}{lll}
\hline Description & Frequencies $\mathbf{N = 9 7 6}$ & Percentages \% \\
\hline Met PTSD Criteria & 269 & 27.6 \\
Did not meet Criteria & 707 & 72.4 \\
\hline
\end{tabular}

Table 2 shows the prevalence of PTSD among respondents. A total of $976(100 \%)$ respondents were screened at baseline. Those who met the criteria for PTSD were $269(27.6 \%)$ whilst $707(72.4 \%)$ did not meet the criteria for PTSD.

\section{Discussion}

An assessment of the respondents' socio-demographic variables showed that there were significant mean differences between the respondents' county of residence. Respondents who lived in other counties reported the highest PTSD mean symptoms. This indicated that PTSD was more common in counties other than Nairobi and Machakos.

The prevalence of PTSD was at 27.6\%. Previous studies have documented PTSD prevalence used different PTSD screens hence, are incomparable with this study. Despite this, the prevalence documented was consistent with the study by Atwoli [12] which documented PTSD prevalence at $28.8 \%$ in Uasin Gishu County, Kenya. The documented prevalence was for 10-18-year-olds living in the streets unlike in the present study where boys from secondary schools were recruited for the study. This implies that children and adolescents who lived in the streets were more susceptible to PTSD. It may also suggest that a roof over one's head may act as a protective factor against PTSD.

One of the oldest studies in Kenya relating to PSTD the prevalence was documented at 50.5\%, whilst 386 (34.8\%) met the partial criteria for PTSD [13]. The participants were 1,110 students recruited from secondary schools in Nairobi, Kenya with a mean age of $16.6( \pm 1.5)$. This prevalence rate is the highest documented with regards to secondary schools in Kenya. The findings indicated that those who live in urban centers are more likely to develop PTSD due to the high exposure to violence.

The finding was also inconsistent with the present study. Several reasons accounted for this inconsistency. For example, respondents were recruited from Northern and 
Central Kenya hence, represented a different geographical area. The prevalence was also higher at $34.5 \%$, from the sampled 477 students [14]. This may indicate that the respondents had been exposed to more traumatic events in comparison to the respondents' in the present study. In light of the present study, these findings also indicated that in Karsberg's (2012) study, respondents had been exposed to more traumatic events. This is consistent with research which has shown that exposure to multiple traumatic events as a risk factor in the development of PTSD [9]. It may also suggest that the respondents had experienced traumatic events which were more intense and severe as compared to the respondents in the selected secondary schools.

On the other hand, the findings of this study were inconsistent with the findings obtained in the study by Liu [15]. From the study 1,125 adolescents who had experienced the Wenchuan earthquake of 2008 documented the prevalence at $23.4 \%$. From this finding, it can be inferred that adolescents who present with PTSD as a result of exposure to other (non-natural disasters) traumatic events may be higher in comparison to PTSD due to natural disasters. This may imply that adolescents who experienced a natural disaster and particularly earthquakes do not cause detrimental effects in comparison to exposure to other traumatic events. This is due to the fact that natural disasters are perceived as being out of human control and for this reason, are easier to accept as compared to traumatic events inflicted by man [16].

From the findings, the respondents' who had been at the schools for less than 12 months reported the highest mean PTSD symptoms. This may suggest that respondents' who had been at the schools for a shorter period presented with more PTSD symptoms. This finding may suggest that they already had PTSD before joining the schools. It can also be speculated that the respondents' were in day schools prior to joining the current schools hence, were more susceptible to exposure to traumatic events.

All in all, the findings of this study showed that PTSD was relatively high amongst the sampled boys' schools at $27.6 \%$. However, this prevalence rate was lower compared to other studies in the county which have documented the prevalence at $50.5 \%$ and $34.5 \%$.

\section{Conclusion}

The findings of this study indicated that the prevalence of PTSD in secondary schools located in Machakos County was high at $27.6 \%$. For this reason, there's a need for future research to investigate the reason(s) behind this high prevalence rate among secondary schools in Kenya. It is also crucial for clinicians in the area of trauma to intervene since the effects of PTSD are likely to last a lifetime if left untreated. It was also observed that respondents who did not reside in neither Nairobi County nor Machakos County reported the highest mean PTSD scores. This indicated that despite respondents from other counties forming the least number of respondents, they reported a higher PTSD mean. It is therefore recommended that the Ministry of Health should set aside funds in secondary schools for treating students who present with PTSD. This would go a long way in buffering the adolescents from comorbid diseases and psychological disorders. It is also recommended that the Ministry of Education and the Ministry of Health work in a collaborative fashion in order to alleviate the prevalence rate of PTSD in secondary schools. It is further suggested that schools should employ non-teaching staff with a proven track record of treating adolescents with PTSD and its comorbidity.

\section{Ethics}

Approvals to conduct the study was obtained from Daystar University Ethics Board, the National Council for Science and Technology in Kenya (NACOSTI), the Ministry of Education and from the School Administrators where the study was conducted.

\section{Limitations}

This study only looked at the prevalence of PTSD symptoms in boys' schools. It would be interesting to investigate the prevalence of PTSD in girls' only schools and mixed schools. Firstly, to see if the findings differ. Secondly, to see whether new insights would be generated.

\section{Conflict of Interest}

The authors declare that they have no competing interests.

\section{Acknowledgements}

Data Analyst: Freda Wanjala, Research Assistants: Dorcas Mutuku, Mary Munyoli and Ruth Omondi.

\section{References}

[1] Marthoenis, Meutia, I., Sofyan, H., \& Schouler-Ocak, M. (2018). Exposure to Traumatic Events and PTSD in a Postconflict and Disaster-Prone Area. Journal of Loss and $\begin{array}{llll}\text { Trauma, } & 23 & \text { (2), } & 128-139 .\end{array}$ https://doi.org/10.1080/15325024.2018.1423867

[2] Bernhard, A., Martinelli, A., Ackermann, K., Saure, D., \& Freitag, C. M. (2018). Association of trauma, Posttraumatic Stress Disorder and Conduct Disorder: A systematic review and meta-analysis. Neuroscience \& Biobehavioral Reviews, 91, 153-169. https://doi.org/10.1016/j.neubiorev.2016.12.019

[3] Mc Farlane, A. C. (2010). The long-term costs of traumatic stress: Intertwined physical and psychological consequences. World Psychiatry, 9 (1), 3-10. https://doi.org/10.1002/j.20515545.2010.tb00254.x

[4] Horesh, D., \& Brown, A. D. (2018). Editorial: Post-traumatic Stress in the Family. Frontiers in Psychology, 9. https://doi.org/10.3389/fpsyg.2018.00040 
[5] Mauritz, M. W., Van Gaal, B. G. I., Jongedijk, R. A., Schoonhoven, L., Nijhuis-van der Sanden, M. W. G., \& Goossens, P. J. J. (2016). Narrative exposure therapy for posttraumatic stress disorder associated with repeated interpersonal trauma in patients with severe mental illness: A mixed methods design. European Journal of $\begin{array}{llll}\text { Psychotraumatology, } & 7 & \text { (1), } & 32473 .\end{array}$ https://doi.org/10.3402/ejpt.v7.32473

[6] Alisic, E., Zalta, A. K., van Wesel, F., Larsen, S. E., Hafstad, G. S., Hassanpour, K., \& Smid, G. E. (2014). Rates of posttraumatic stress disorder in trauma-exposed children and adolescents: Meta-analysis. British Journal of Psychiatry, 204 (05), 335-340. https://doi.org/10.1192/bjp.bp.113.131227

[7] Olff, M. (2017). Sex and gender differences in post-traumatic stress disorder: An update. European Journal of $\begin{array}{lll}\text { Psychotraumatology, } \quad 8 \quad \text { (sup4), } & 1351204 .\end{array}$ https://doi.org/10.1080/20008198.2017.1351204

[8] Garza, K., \& Jovanovic, T. (2017). Impact of Gender on Child and Adolescent PTSD. Current Psychiatry Reports, 19 (11), 87. https://doi.org/10.1007/s11920-017-0830-6

[9] McLaughlin, K. A., Koenen, K. C., Hill, E. D., Petukhova, M., Sampson, N. A., Zaslavsky, A. M., \& Kessler, R. C. (2013). Trauma Exposure and Posttraumatic Stress Disorder in a National Sample of Adolescents. Journal of the American Academy of Child \& Adolescent Psychiatry, 52 (8), 815830.e14. https://doi.org/10.1016/j.jaac.2013.05.011

[10] Jenkins, R., Othieno, C., Omollo, R., Ongeri, L., Sifuna, P., Mboroki, J., Kiima, D., \& Ogutu, B. (2015). Probable Post Traumatic Stress Disorder in Kenya and Its Associated Risk Factors: A Cross-Sectional Household Survey. International
Journal of Environmental Research and Public Health, 12 (10), 13494-13509. https://doi.org/10.3390/ijerph121013494

[11] Foa, E. B., Asnaani, A., Zang, Y., Capaldi, S., \& Yeh, R. (2018). Psychometrics of the Child PTSD Symptom Scale for DSM-5 for Trauma-Exposed Children and Adolescents. Journal of Clinical Child \& Adolescent Psychology, 47 (1), 38-46. https://doi.org/10.1080/15374416.2017.1350962

[12] Atwoli, L., Ayuku, D., Hogan, J., Koech, J., Vreeman, R. C., Ayaya, S., \& Braitstein, P. (2014). Impact of Domestic Care Environment on Trauma and Posttraumatic Stress Disorder among Orphans in Western Kenya. PLoS ONE, 9 (3), e89937. https://doi.org/10.1371/journal.pone.0089937

[13] Ndetei, D. M., Ongecha-Owuor, F. A., Khasakhala, L., Mutiso, V., Odhiambo, G., \& Kokonya, D. A. (2009). Traumatic experiences of Kenyan secondary school students. Journal of Child \& Adolescent Mental Health, 19, 147-155. https://doi.org/10.2989/17280580709486650

[14] Karsberg, S. H., \& Elklit, A. (2012). Victimization and PTSD in A Rural Kenyan Youth Sample. Clinical Practice \& Epidemiology in Mental Health, 8 (1), 91-101. https://doi.org/10.2174/1745017901208010091

[15] Liu, Q., Jiang, M., Yang, Y., Zhou, H., Zhou, Y., Yang, M., Xu, H., \& Ji, Y. (2019). Prevalence of Posttraumatic Stress Disorder (PTSD) and Its Correlates Among Junior High School Students at 53 Months After Experiencing an Earthquake. Disaster Medicine and Public Health Preparedness, 13 (03), 414-418. https://doi.org/10.1017/dmp.2018.76 